\title{
Effets comparés des traitements à l'ammoniac et à la soude sur la valeur alimentaire de fourrages pauvres
}

\author{
J.P. DULPHY, A. KOMAR * et P. ZWAENEPOEL ** \\ avec la collaboration technique de L. L'Hotelier, H. Bousquet, Marie Jailler, \\ Jacqueline JAMOT et Madeleine Dudilieu \\ I.N.R.A., Laboratoire des Aliments, C.R.Z.V. de Theix \\ F 63122 Ceyrat \\ " Faculty of Animal Husbandry, Padjadjaran State University \\ Bukit Dago Utara Street, Bandung, West Java, Indonesia \\ *:s C.E.M.A.G.R.E.F., Echelon de Montoldre, F 03150 Varennes-sur-Allier
}

\section{Résumé}

Dans 3 essais avec des fourrages pauvres (un foin de graminées tardif, une paille de blé et une paille de riz) nous avons comparé les effets d'un traitement à la soude avec ceux d'un traitement à l'ammoniac anhydre. Le traitement à l'ammoniac $\left(40 \mathrm{~g}\right.$ de $\mathrm{NH}_{3} / \mathrm{kg}$ de fourrage) a été effectué en tas, à l'extérieur, sous bâche hermétique, au mois d'août. Le traitement à la soude était effectué 48 heures avant la distribution aux animaux par un procédé semi-humide $(2,51$ de solution à $16 \mathrm{~g}$ de soude par litre pour chaque $\mathrm{kg}$ de fourrage).

Les fourrages non traités et traités ont été distribués de la façon suivante à des moutons normaux :

- fourrage non traité, à volonté ;

— fourrage traité à l'ammoniac, à volonté ;

— fourrage traité à la soude, à volonté ; traité ;

- fourrage traité à l'ammoniac, en quantité limitée proche de celle du fourrage non

— fourrage traité à la soude, en quantité limitée également (pour la paille de riz seulement).

La paille de blé a, en outre, été distribuée à des animaux fistulisés du rumen et selon les 5 modalités décrites ci-dessus.

La paille de blé et celle de riz ont été complémentées en énergie et azote. Avec celle de riz on a aussi comparé l'influence des deux types d'aliment concentré (maïs-grain ou pulpe de betterave).

Le traitement à l'ammoniac a augmenté la teneur en matières azotées totales (MAT) des trois fourrages, surtout pour le foin $(+87 \mathrm{~g} / \mathrm{kg}$ de MS pour ce dernier). Cependant, pour la paille de blé, la teneur en MAT n'a atteint que $85 \mathrm{~g} / \mathrm{kg}$ de MS, ce qui est un peu faible.

Les deux traitements ont augmenté nettement l'ingestibilité des fourrages étudiés, de 
façon comparable pour le foin et la paille de blé ( +37 p. 100 en moyenne). Pour la paille de riz le traitement à la soude a été plus efficace $(+62$ contre +31 p. 100).

Les deux traitements ont augmenté la digestibilité de la matière organique $(+8,9$ points pour l'ammoniac et $+9,8$ points pour la soude), surtout pour les palles et, dans ce cas, la soude a été plus efficace que l ammoniac. Le remplacement du concentre «maïs» par celui à base de pulpe a eu peu d'effet sur les digestıbilités de la paille de riz traitée ou non à l'ammoniac.

Le traitement à l'ammoniac a augmenté fortement la teneur en matières azotées non digestibles des fourrages $(+22 \mathrm{~g} / \mathrm{kg}$ MS). De même, le concentré «maïs » a augmenté légèrement cette teneur par rapport au concentré "pulpe». Par contre, la rétention d'azote par les animaux a été plus élevée, pour la ration a base de paille de blé, lorsque celle-ci avait été traitée à la soude.

Pour cette ration, à base de paille de blé, la concentration en acides gras volatils dans le rumen a été plus élevée avec le traitement a la soude que celui à l'ammoniac ( 88 contre 78 mmoles/litre). A l'inverse, celle en $\mathrm{NH}_{3}$ a été la plus élevée avec la paille traitée à l'ammoniac $(25 \mathrm{mg} / 100 \mathrm{ml})$, sans que les concentrations soient dangereuses, et la plus faible avec la paille traitée à la soude $(12 \mathrm{mg} / 100 \mathrm{ml})$.

Les traitements de la paille, surtout celui à l'ammoniac, ont abaissé l'activité cellulolytique de la microflore ruminale des moutons.

Tous ces résultats sont discutés. Malgré une très légère infériorité par rapport au traitement à la soude au niveau de la valeur alimentaire, le traitement à l'ammoniac permet une amélioration notable des fourrages pauvres. La question de la valeur azotée des fourrages traités ainsi demeure cependant posée ainsi que le problème de la signification de la faible activité cellulolytique induite par leur ingestion.

Mots clés : Foin, paille, traitement basique, ingestibilité, digestibilité.

\section{Introduction}

Après le traitement à la soude (JACKson, 1977), celui à l'ammoniac semble maintenant retenir le plus l'attention de ceux qui sont préoccupés par l'utilisation des fourrages pauvres. Ce traitement présente, sur celui à la soude, l'avantage d'apporter en même temps de l'azote dans les fourrages (WaIss et al., 1972 ; SUNDSToL et al., 1978 ; Kernan et al., 1979 ; CoRdesse \& TABAtabaï, 1981...). Il améliore la digestibilité de ces fourrages ainsi que leur ingestibilité (HARTLEY \& JONES, 1978 ; SUNDSTOL et al., 1979 ; Solaiman et al., 1979 ; Lawlor \& O’Shea, 1979 ; Cordesse, 1982).

L'efficacité du traitement à l'ammoniac est cependant très variable. Elle est améliorée par une augmentation de la température du fourrage, de son humidité et par la durée du traitement (SundSTol et al., 1978). Les conclusions de chaque essai doivent donc être tirées en tenant compte de ces conditions de traitement.

En nous limitant à la seule technique de traitement en meules (SUnDstó et al., 1978) nous avons étudié trois fourrages relativement différents : un foin peu digestible, une paille de blé et une paille de riz. Nous avons comparé cette technique à un traitement à la soude, ainsi que l'ont déjà fait HARTLEY \& Jones (1978). Ces fourrages ont été distribués à des moutons, à volonté, ou en quantité limitée, en faisant varier la nature et le niveau de complémentation dans la ration.

En effet, l'étude des pailles traitées ou non à la soude (Dulphy et al., 1982 a et $\mathrm{b}$; $1983 \mathrm{a}$ et $\mathrm{b}$ ) nous a montré l'influence, parfois importante, des conditions dans lesquelles ces pailles étaient distribuées sur leur valeur alimentaire pour des ruminants. 
Une bonne valorisation des fourrages pauvres nécessite le recours à un traitement efficace, mais aussi à une complémentation (nature, niveau...) qui ne limite pas l'effet de ce traitement.

Dans ces nouveaux essais notre objectif était donc aussi d'examiner les variations de valeur alimentaire des fourrages traités en les distribuant dans différentes conditions (Dulphy et al., 1982 b et Dulphy et al., 1983 a).

Nous avons en outre profité de ce travail pour étudier certains aspects de la digestion et de l'utilisation des pailles traitées à la soude ou à l'ammoniac :

- activité cellulolytique dans le rumen,

- caractéristiques du jus de rumen,

- rétention de l'azote par les animaux.

\section{Matériel et méthodes}

\section{A. Fourrages et traitements}

Les caractéristiques des trois fourrages étudiés sont rapportés dans le tableau 1. Chacun d'entre eux a été traité à l'ammoniac et à la soude.

\section{Tableau 1}

Composition chimique des fourrages utilisés

Chemical composition of the different roughages

\begin{tabular}{|c|c|c|c|c|c|c|}
\hline \multirow[b]{2}{*}{$\begin{array}{l}\text { Essai } \\
\text { Trial }\end{array}$} & \multirow[b]{2}{*}{$\begin{array}{l}\text { Fourrage } \\
\text { Roughage }\end{array}$} & \multirow[b]{2}{*}{$\begin{array}{l}\text { Traitement } \\
\text { Treatment }\end{array}$} & \multirow{2}{*}{$\begin{array}{c}\text { Teneur } \\
\text { en matière } \\
\text { sèche }(\%) \\
\text { DM content } \\
(\%)\end{array}$} & \multicolumn{3}{|c|}{$\begin{array}{c}\text { Teneur en } \mathrm{g} / 100 \mathrm{~g} \text { de } \mathrm{MS} \\
\text { Content } \mathrm{g} / 100 \mathrm{~g} D M \text { of }\end{array}$} \\
\hline & & & & $\begin{array}{c}\text { Matières } \\
\text { minérales } \\
\text { Ashes }\end{array}$ & $\begin{array}{c}\text { Matières } \\
\text { azotées } \\
\text { totales } \\
\text { Total crude } \\
\text { protein }\end{array}$ & $\begin{array}{c}\text { Cellulose } \\
\text { brute } \\
\text { Crude } \\
\text { fibre }\end{array}$ \\
\hline I & $\begin{array}{l}\text { Foin } \\
\text { Hay }\end{array}$ & $\begin{array}{c}\mathrm{O} \\
\mathrm{NH}_{3} \\
\mathrm{Na} \mathrm{OH}\end{array}$ & $\begin{array}{l}87,3 \\
87,2 \\
26,9\end{array}$ & $\begin{array}{l}4,6 \\
4,5 \\
9,8\end{array}$ & $\begin{array}{r}9,0 \\
17,7 \\
9,1\end{array}$ & $\begin{array}{l}35,8 \\
36,4 \\
34,3\end{array}$ \\
\hline II & $\begin{array}{l}\text { Paille de blé } \\
\text { Wheat-straw }\end{array}$ & $\begin{array}{c}\mathrm{O} \\
\mathrm{NH}_{3} \\
\mathrm{Na} \mathrm{OH}\end{array}$ & $\begin{array}{l}88,5 \\
86,2 \\
27,7\end{array}$ & $\begin{array}{l}11,6 \\
12,3 \\
14,5\end{array}$ & $\begin{array}{l}3,2 \\
8,5 \\
2,7\end{array}$ & $\begin{array}{l}43,7 \\
45,7 \\
41,5\end{array}$ \\
\hline III & $\begin{array}{l}\text { Paille de riz } \\
\text { Rice-straw }\end{array}$ & $\begin{array}{c}\mathrm{O} \\
\mathrm{NH}_{3} \\
\mathrm{Na} \mathrm{OH}\end{array}$ & $\begin{array}{l}90,1 \\
89,6 \\
28,3\end{array}$ & $\begin{array}{l}15,0 \\
14,4 \\
17,3\end{array}$ & $\begin{array}{r}3,7 \\
10,0 \\
3,1\end{array}$ & $\begin{array}{l}36,7 \\
37,7 \\
33,3\end{array}$ \\
\hline
\end{tabular}


Pour le traitement à l'ammoniac les fourrages ont été disposés en tas à l'extérieur sous bâche hermétique. A la base de chaque tas l'ammoniac a été versé dans un récipient. Le traitement ayant été effectué en août, l'ammoniac s'est vraisemblablement rapidement réparti dans les fourrages. Les tas ont été découverts et les fourrages traités rentrés à l'abri deux mois après l'introduction de l'ammoniac. La dose utilisée pour traiter a été de $40 \mathrm{~g}$ de $\mathrm{NH}_{3} / \mathrm{kg}$ de fourrage.

Le traitement à la soude a été effectué au fur et à mesure de la distribution aux animaux, exactement 2 jours avant, par le procédé semi-humide, c'est-à-dire en ajoutant à chaque $\mathrm{kg}$ de paille 2,51 d'une solution contenant $16 \mathrm{~g}$ de soude par litre. Ce mode de traitement a été choisi car il est facile à mettre en œuvre et son efficacité est très bonne (DulPhy et al., $1982 \mathrm{a}$ ).

\section{B. Schémas expérimentaux}

\section{Foin et paille de blé}

Pour chaque essai, à partir d'un groupe de 20 moutons, nous avons constitué 4 lots aussi semblables que possible sur la base du poids vif. Ces lots ont reçu, simultanément :

- le fourrage non traité, à volonté,

- le fourrage traité à l'ammoniac, à volonté,

- le fourrage traité à la soude, à volonté,

- le fourrage traité à l'ammoniac, en quantité limitée proche de celle du fourrage non traité.

Avec la paille de blé les moutons ont reçu en outre $320 \mathrm{~g}$ d'un aliment concentré D contenant 51,6 p. 100 de maïs grain, 42,2 p. 100 de tourteau de soja et 6,2 p. 100 de minéraux, aliment identique à celui utilisé par Xande (1978).

Les différents types de paille de blé ont également été distribués à des moutons fistulisés du rumen (deux par traitement) qui ont reçu les rations suivantes :

— paille non traitéc, à volonté,

- paille traitée à l'ammoniac, à volonté,

- paille traitée à la soude, à volonté,

- paille traitée à l'ammoniac, en quantité limitée,

- paille traitée à la soude, en quantité limitée,

avec, dans tous les cas, $320 \mathrm{~g}$ d'aliment concentré par jour.

\section{Paille de riz (*)}

Avec la paille de riz nous avons voulu mesurer l'effet de la nature et de la proportion de concentré dans la ration sur la digestibilité du fourrage traité ou non. Le schéma expérimental utilisé est donné dans le tableau 2. La composition des concentrés utilisés est reportée dans le tableau 3. Chaque lot d'animaux comprenait 6 moutons.

(*) Cette paille nous a été fournie par X. Garambois dé l'I.N.R.A. (E.N.S.A. de Montpellier). Qu'il en soit ici remercié. 


\section{TABLEAU 2}

Schéma expérimental de l'essai "paille de riz».

Experimental design of the «rice straw» trial.

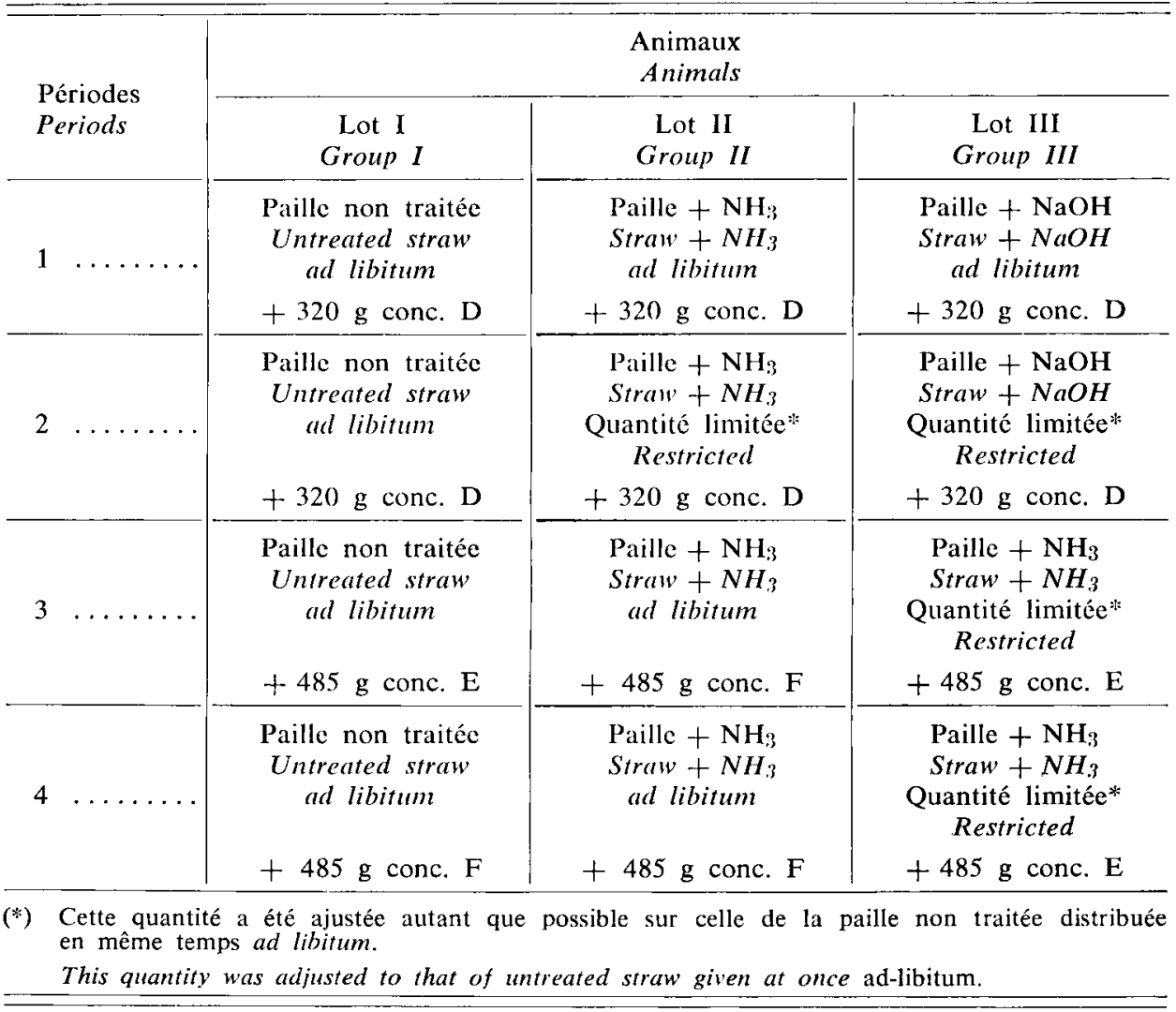

\section{Animaux}

Les animaux ayant servi à l'étude de nos fourrages étaient des moutons mâles castrés, de race Texel, pesant respectivement $75 \mathrm{~kg}$ pour le foin, et $60 \mathrm{~kg}$ pour les deux pailles. Ceux-ci étaient adaptés à leur régime pendant 2, voire 3 semaines, et placés en cage à métabolisme, auxquelles ils étaient déjà bien habitués, 4-5 jours avant le début de la période de mesures qui durait 6 jours.

\section{Mesures}

Nous avons mesuré, sur les animaux utilisés, la digestibilité et l'ingestibilité des rations correspondant aux traitements décrits plus haut. Les animaux recevaient 2 repas par jour ( $8 \mathrm{~h}$ et $16 \mathrm{~h}$ ) comprenant la moitié de l'aliment concentré (lorsqu'ils en 
recevaient), qu'ils ingéraient rapidement, puis le fourrage. Les fourrages ont toujours été présentés après avoir été grossièrement hachés au hache-paille. Pour les distributions à volonté on a recherché un pourcentage de refus des fourrages de 10-15 p. 100 .

\section{TABleaU 3}

Composition des aliments concentrés utilisés (\% MS).

Chemical composition of concentrates (DM \%).

\begin{tabular}{|c|c|c|c|c|}
\hline & & $\begin{array}{c}\text { Matières } \\
\text { minérales } \\
\text { Ashes }\end{array}$ & $\begin{array}{c}\text { Matières } \\
\text { azotées totales } \\
\text { Crude protein }\end{array}$ & $\begin{array}{l}\text { Cellulose } \\
\text { brute } \\
\text { Crude fibre }\end{array}$ \\
\hline D & $\begin{aligned} 51,6 \% & \text { de maïs } \ldots \ldots \ldots \ldots \\
& \text { of maize } \\
42,2 \% & \begin{array}{l}\text { de tourteau de soja } \ldots \\
\text { of soya-oil meal }\end{array} \\
6,2 \% & \begin{array}{l}\text { de minéraux } \ldots \ldots \ldots \\
\text { of minerals }\end{array}\end{aligned}$ & 8,3 & 27,8 & 2,1 \\
\hline $\mathrm{E}$ & $\begin{aligned} 68,0 \% & \text { de maïs } \ldots \ldots \ldots \ldots \\
& \text { of maize } \\
27,8 \% & \begin{array}{l}\text { de tourteau de soja } \ldots \\
\text { of soya-oil meal }\end{array} \\
4,2 \% & \begin{array}{l}\text { de minéraux } \ldots \ldots \ldots \\
\text { of minerals }\end{array}\end{aligned}$ & 5,9 & 21,9 & 2,1 \\
\hline $\mathrm{F}$ & $\begin{aligned} 68,0 \% & \begin{array}{l}\text { de pulpe de betteraves } \\
\text { déshydratée ............ }\end{array} \\
& \text { of dried beet pulp } \\
27,8 \% & \begin{array}{l}\text { de tourteau de soja } \ldots \\
\text { of soya-oil méal }\end{array} \\
4,2 \% & \begin{array}{l}\text { de minéraux } \ldots \ldots \ldots \\
\text { of minerals }\end{array}\end{aligned}$ & 9,5 & 21,6 & 13,0 \\
\hline
\end{tabular}

Les résultats de digestibilité ne seront donnés que pour le fourrage seul. Ils ont été calculés (sauf pour le foin) par différence à partir des digestibilités des rations, en supposant que les digestibilités des compléments étaient égales à celles données dans l'ouvrage sur l'alimentation des ruminants (I.N.R.A., 1978).

Avec la paille de blé, l'urine des moutons non fistulés a été recueillie et pesée.

On a en outre prélevé, sur les moutons fistulisés, du jus de rumen pendant 2 jours consécutifs $0,1,2,3,4,6$ et 8 heures après le repas de concentré du matin. Enfin, dans le rumen de ces moutons ont été placés des sachets de nylon contenant $3 \mathrm{~g}$ de paille non traitée broyéc. Ces sachets ont été retirés au bout de $8,24,48$ et 72 heures, afin d'apprécier l'activité cellulolytique du jus de rumen (CHENOST et al., 1970). 
Enfin on a mesuré, selon la même méthode, la cinétique de digestion de la paille de blé, avant et après chacun des traitements, en plaçant les pailles broyées dans des sachets suspendus dans le rumen d'autres moutons recevant un bon foin de luzerne.

\section{Analyses}

Les analyses effectuées ont déjà été décrites par ailleurs (Dulphy et al., 1983 a ; DulPhy et al., 1984).

\section{Résultats}

\section{A. Composition chimique (tabl. 1)}

Le traitement à l'ammoniac a augmenté fortement les teneurs en matières azotées totales des fourrages : $+8,7 ;+5,3$ et $+6,3$ points respectivement pour le foin, la paille de blé et la paille de riz, ce qui correspond à des pourcentages de fixation de l'ammoniac de 42,26 et 31 p. 100 (respectivement $16,8,10,4$ et $12,4 \mathrm{~g}$ de $\mathrm{NH}_{3}$ par $\mathrm{kg}$ de MS de fourrage).

Les teneurs en matières azotées totales (MAT) des rations, non rapportées ici, ont toujours été supérieures à 10 p. 100, sauf pour les deux foins sans ammoniac et le régime à base de paille de riz traitée à la soude et distribué à volonté (MAT = 7,7 p. 100 seulement).

La teneur en cendres des fourrages a été notablement augmenté par le traitement à la soude, qui apporte $0,6 \mathrm{~g}$ de $\mathrm{Na}$ par $\mathrm{g}$ de soude. Cela entraîne d'ailleurs une baisse très légère des teneurs en matières azotées totales et ccllulose brute des fourrages après leur traitement à la soude.

\section{B. Quantités ingérées (tabl. 4, 5 et 6)}

Le traitement à l'ammoniac a augmenté significativement les quantités de matière sèche de fourrages ingérées : respectivement +28 p. $100,+47$ p. 100 et +31 p. 100. Il en a été de même pour le traitement à la soude : respectivement +23 p. 100, +49 p. 100 et +62 p. 100 . Les deux traitements n'ont pas donné de résultats significativement différents, sauf avec la paille de riz pour laquelle le traitement à la soude a été significativement supérieur à celui de l'ammoniac.

Pour la paille de riz, distribuée avec des quantités élevées de concentré, les augmentations d'ingestion après le traitement à l'ammoniac ont été de 40 p. 100 en présence du concentré " amidon" et de 43 p. 100 en présence de celui à base de "pulpe». La nature du concentré n'a donc pas eu d’effet sur les quantités ingérées de paille traitée ou non à l'ammoniac. 
TABleau 4

Valeurs alimentaires du foin étudié.

Feeding values of the hay.

\begin{tabular}{|c|c|c|c|c|c|}
\hline & \multirow[b]{2}{*}{ 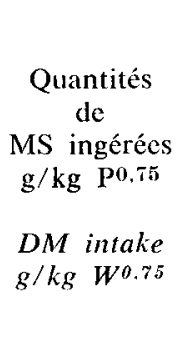 } & \multicolumn{3}{|c|}{$\begin{array}{l}\text { Digestibilité }(\times 100) \\
\text { Digestibilty }(\times 100)\end{array}$} & \multirow{2}{*}{$\begin{array}{c}\text { Teneur } \\
\text { en matière } \\
\text { azotées } \\
\text { non } \\
\text { digestibles } \\
\text { (g/ } \mathrm{kg} \mathrm{MS}) \\
\text { Indigestible } \\
\text { crude } \\
\text { protein } \\
\text { (g/kg DM }\end{array}$} \\
\hline & & $\begin{array}{c}\text { Matière } \\
\text { organique } \\
\text { Organic } \\
\text { matter }\end{array}$ & $\begin{array}{l}\begin{array}{c}\text { Cellulose } \\
\text { brute }\end{array} \\
\text { Crude fibre }\end{array}$ & $\begin{array}{c}\text { Matières } \\
\text { azotées } \\
\text { totales } \\
\text { Crude } \\
\text { protein }\end{array}$ & \\
\hline $\begin{array}{l}\text { Foin normal ad libi- } \\
\text { tum } \ldots \ldots \ldots \ldots \ldots \ldots \\
\text { Normal hay }\end{array}$ & $44,2 \pm 3,9^{a}$ & $58,0^{\mathrm{a}}$ & 65,8 & 44,4 & 50 \\
\hline $\begin{array}{l}\text { Foin traité avec } \mathrm{NH}_{3} \\
\text { ad libitum } \ldots \ldots \ldots \\
\mathrm{NH}_{3} \text {-treated hay }\end{array}$ & $56,4 \pm 2,8^{b}$ & $64,3 \mathrm{~b}$ & 76,6 & 55,8 & 78 \\
\hline $\begin{array}{l}\text { Foin traité avec } \mathrm{NaOH} \\
\text { ad libitum } \ldots . . . \\
\mathrm{NaOH} \text { treated hay }\end{array}$ & $54,3 \pm 9,9^{b}$ & $65,9^{b}$ & 78,8 & 40,1 & 55 \\
\hline $\begin{array}{l}\text { Foin traité avec } \mathrm{NH}_{3} \\
\text { en quantité limitée. } \\
\mathrm{NH}_{3} \text { treated hay, res- } \\
\text { tricted }\end{array}$ & $40,9 \pm 2,5^{a}$ & $66,8^{b}$ & 79,4 & 59,0 & 73 \\
\hline
\end{tabular}

C. Digestibilité de la matière organique et de la cellulose brute (tabl. 4,5 et 6 )

Le traitement à l'ammoniac a toujours significativement augmenté la digestibilité : respectivement $+6,3$, $+15,8$ et $+4,6$ points pour la matière organique, $+10,8$, $+15,2$ et $+10,9$ points pour la cellulose brute, avec le foin, la paille de blé et la paille de riz distribués à volonté. Lorsque les fourrages traités ont été distribués en quantité comparable à celle des fourrages non traités les augmentations de digestibilité de la matière organique ont été respectivement de $+8,8 ;+15,5$ et $+10,3$ points. 


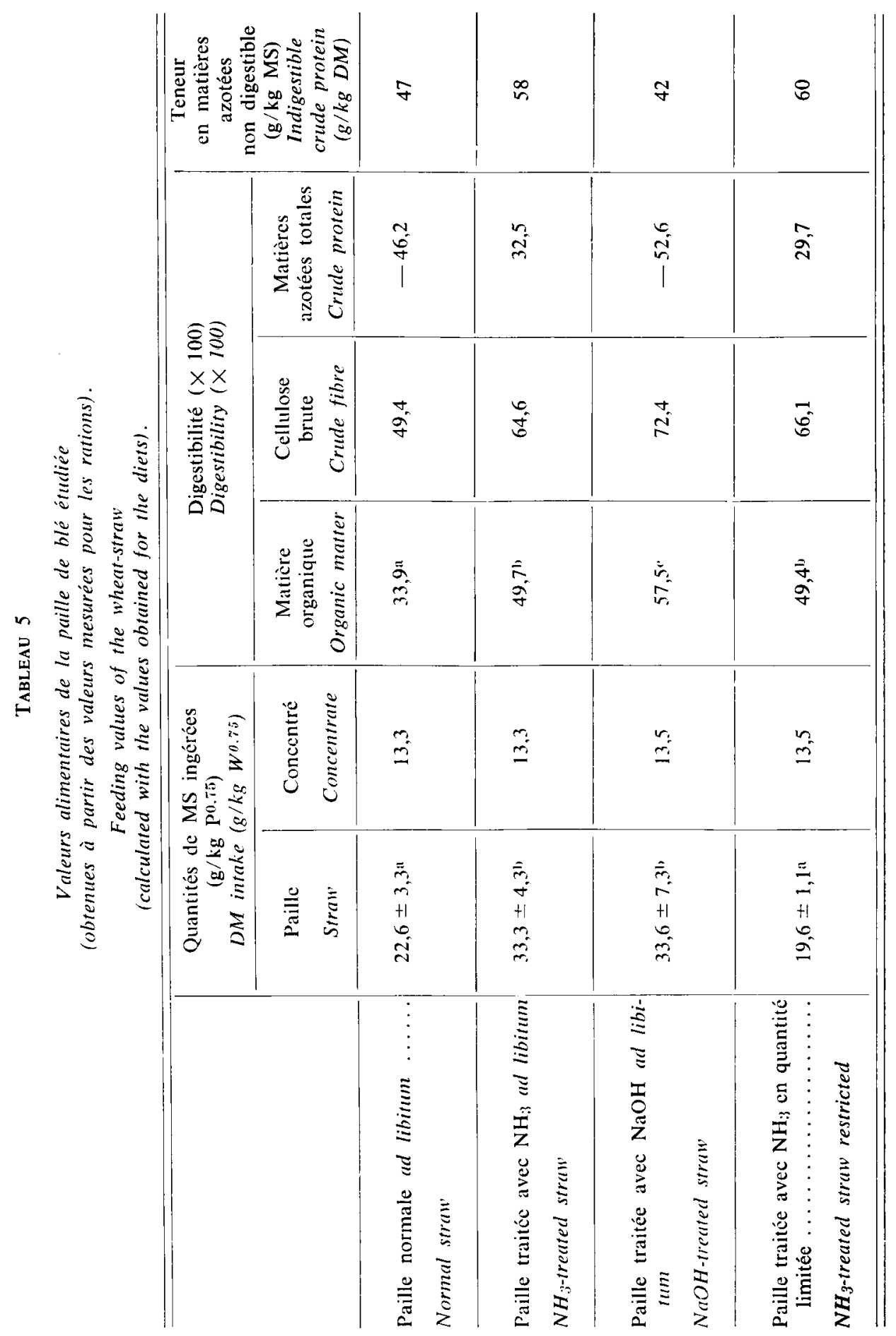




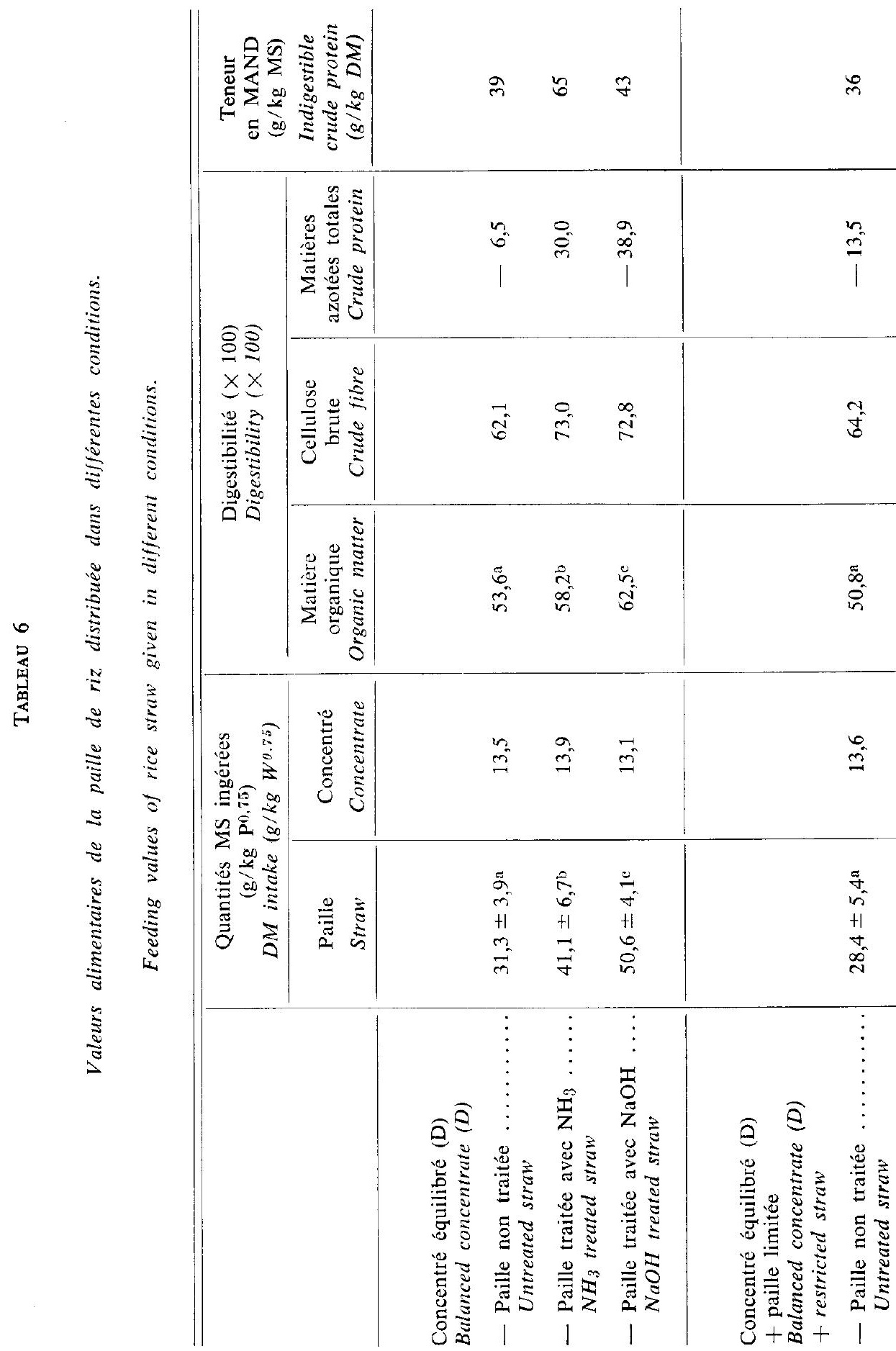




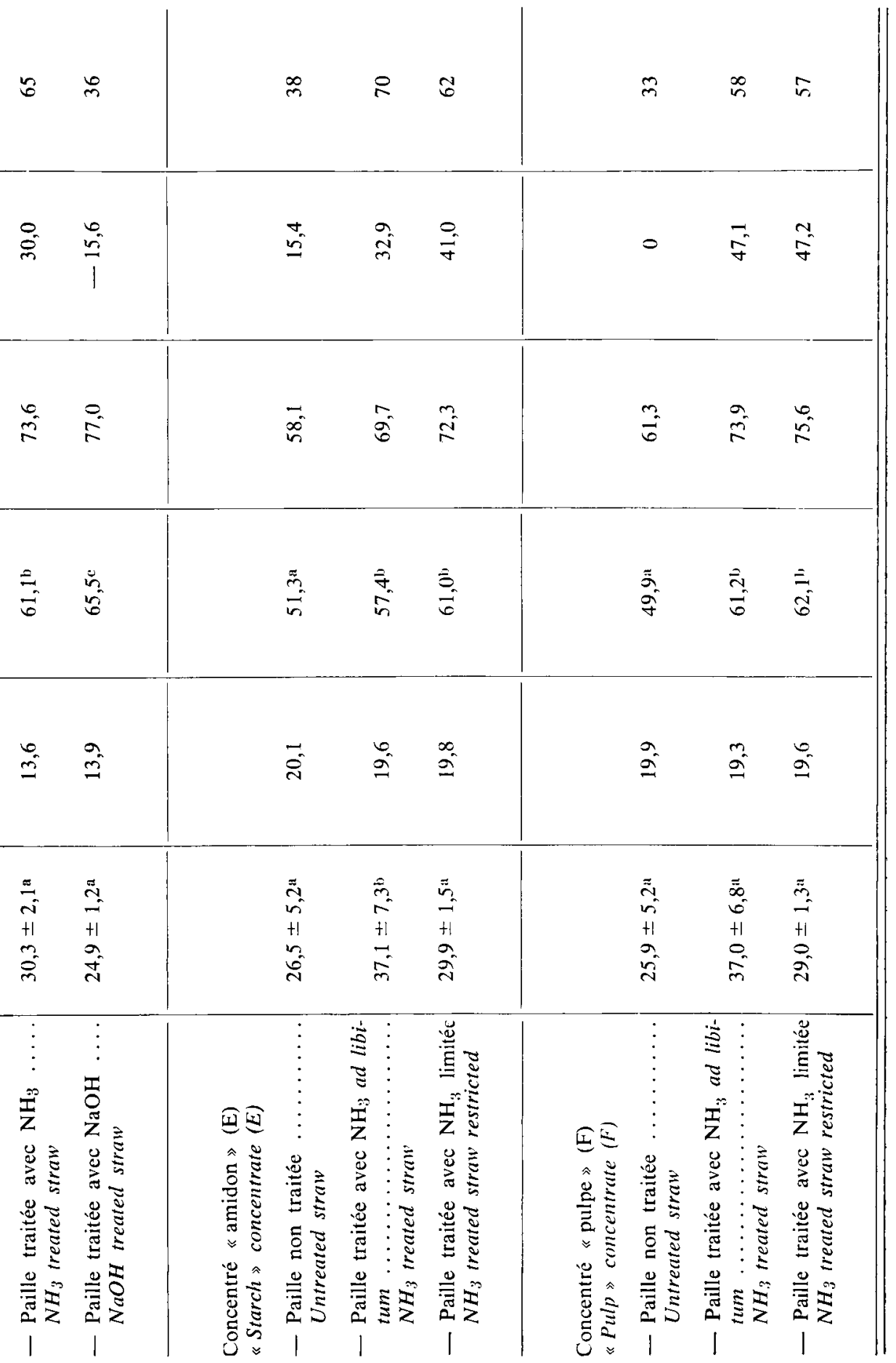


Le traitement à la soude a également augmenté significativement la digestibilité de la matière organique des fourrages distribués à volonté : respectivement $+7,9$, $+23,6$ et $+8,9$ points.

Dans le cas des deux pailles, le traitement à la soude a donné des résultats significativement supérieurs à ceux du traitement à l'ammoniac.

L'augmentation de la teneur en amidon dans la ration n'a pratiquement pas modifié la digestibilité de la paille de riz non traitée, ni d'ailleurs celle de la paille traitée à l'ammoniac : respectivement $-2,3$ et $-0,8$ points pour la matière organique, mais $-4,0$ et -3.3 points pour la cellulose brute. Distribuée en quantité limitée, la paille traitéc à l'ammoniac a eu la même digestibilité de 61-62 en présence des 3 concentrés.

La substitution du concentré «amidon» (E) par le concentré «pulpe » (F) a augmenté légèrement la digestibilité de la matière organique de la paille traitée à l'ammoniac : $+3,8$ points à volonté (différence significative), mais seulement $+1,1$ point en quantité limitée (différence non significative). Les valeurs correspondantes ont été $+4,2$ et $+3,3$ points pour la cellulose brute.

\section{Digestibilité des matières azotées totales}

Les digestibilités des matières azotées totales sont rapportées dans les tableaux 4 , 5 et 6 mais, compte tenu des modifications des teneurs induites par le traitement à l'ammoniac, il nous a paru préférable de comparer les teneurs en matières azotées non digestibles (MAND) qui dépendent beaucoup moins des teneurs en matières azotées.

Ces teneurs en MAND ont été fortement augmentées par le traitement à l'ammoniac : respectivement de +28 , +11 et $+28 \mathrm{~g} / \mathrm{kg}$ de MS pour le foin, la paille de blé et la paille de riz distribués à volonté et de $+23,+13$ et $+28 \mathrm{~g}$ pour les mêmes fourrages distribués en quantité comparable aux fourrages non traités. En revanche, le traitement à la soude n'a pratiquement pas augmenté les teneurs en MAND.

Pour la paille de riz traitée à l'ammoniac ces teneurs ont varié légèrement avec l'augmentation de la teneur en amidon dans la ration : $+5 \mathrm{~g} / \mathrm{kg}$ de MS lorsque la paille était à volonté, mais $-3 \mathrm{~g}$ lorsqu'elle était limitée.

Le remplacement du concentré " amidon " par la "pulpe » a entrâné une baisse notable des teneurs en MAND de la paille non traitée et de celle traitéc à l'ammoniac : -5 à $-12 \mathrm{~g} / \mathrm{kg}$ de MS.

\section{E. Rétention azotée}

Les quantités d'azote ingérées et excrétées dans les fèces et les urines figurent, pour les rations à base de paille de blé, dans le tableau 7 . On y observe que la rétention d'azote la plus élevée a été obtenue avec la ration de paille traitée à la soude (15,9 p. 100 de l'ingéré). Les rétentions pour la ration de paille traitée à l'ammoniac ont été plus faibles : respectivement 5 et 8,1 p. 100 à volonté et en quantité limitée. 
Tableau 7

Résultats des bilans azotés effectués avec les régimes à base de paille de blé. Nitrogen retention with diets based on wheat-straw.

\begin{tabular}{|c|c|c|c|c|c|}
\hline \multirow[b]{2}{*}{$\begin{array}{l}\text { Type de paille } \\
\text { Straw }\end{array}$} & \multirow[b]{2}{*}{$\begin{array}{l}\mathrm{N} \text { ingéré } \\
\text { Ingested } N \\
\text { g/jour } \\
\text { g/day }\end{array}$} & \multirow{2}{*}{$\begin{array}{l}\text { N excrété } \\
\text { dans } \\
\text { les fèces } \\
\text { Fecal } N \\
\mathrm{~g} / \text { jour } \\
\text { g/day }\end{array}$} & \multirow{2}{*}{$\begin{array}{l}\text { N excrété } \\
\text { dans } \\
\text { l'urine } \\
\text { Urinary } N \\
\text { g/jour } \\
\text { g/day }\end{array}$} & \multicolumn{2}{|c|}{$\begin{array}{c}\mathrm{N} \text { retenu } \\
\text { Retained } N\end{array}$} \\
\hline & & & & $\begin{array}{l}g / \text { jour } \\
g / d a y\end{array}$ & $\begin{array}{c}\text { En \% } \\
\text { de } \\
\text { l'ingéré } \\
\% \\
\text { ingested }\end{array}$ \\
\hline $\begin{array}{l}\text { Non traitée } \ldots \ldots \ldots \\
\text { Untreated }\end{array}$ & $14,69 \pm 0,86$ & $4,01 \pm 2,18$ & $10,64 \pm 1,14$ & $+0,04 \pm 1,24^{a}$ & 0,3 \\
\hline $\begin{array}{l}\text { Traitée avec } \mathrm{NH}_{3} \text { ad } \\
\text { libitum } \ldots \ldots \ldots \ldots \\
\mathrm{NH}_{3} \text { treated }\end{array}$ & $23,02 \pm 1,90$ & $8,38 \pm 1,67$ & $13,48 \pm 1,08$ & $+1,15 \pm 1,35^{\mathrm{ac}}$ & 5,0 \\
\hline $\begin{array}{c}\text { Traitée avec } \mathrm{NaOH} \text { ad } \\
\quad \text { libitum } \ldots \ldots \ldots \ldots\end{array}$ & $16,14 \pm 0,66$ & $6,40 \pm 1,41$ & $7,18 \pm 1,46$ & $+2,56 \pm 0,68^{\mathrm{b}}$ & 15,9 \\
\hline $\begin{array}{c}\text { Traitée avec } \mathrm{NH}_{3} \text { li- } \\
\text { mitée } \ldots \ldots \ldots \ldots \ldots \\
\mathrm{NH}_{3} \text { treated restricted }\end{array}$ & $18,80 \pm 0,13$ & $5,48 \pm 0,45$ & $11,79 \pm 0,37$ & $+1,53 \pm 0,27$ lke & 8,1 \\
\hline
\end{tabular}

F. Caractéristiques du jus de rumen

Les caractéristiques du jus de rumen des animaux recevant les rations de paille de blé sont rapportées dans le tableau 8, ainsi que dans la figure 1 .

1. $p H$

Le $\mathrm{pH}$ du jus de rumen des 5 régimes étudiés n'a varié qu'entre 6,4 et 7,0 . Il a été légèrement plus faible pour la ration de paille traitée à l'ammoniac $(-0,15$ par rapport à celle de paille non traitée), et légèrement plus élevé $(+0,15)$ pour la ration de paille traitée à la soude.

\section{Acides gras volatils (AGV)}

La concentration en AGV, pour un régime donné, a peu varié au cours de la journée. Elle a été augmentée significativement par le traitement à l'ammoniac et plus encore par celui à la soude. La limitation de l'ingestion des pailles traitées a réduit cette teneur en $A G V$ à $72-73$ mmoles/l contre 64 pour la paille non traitée distribuée à volonté.

L'orientation des fermentations est restée de type essentiellement acétique, le traitement à l'ammoniac ayant augmenté de 2-3 points la proportion relative d'acide acétique et celui à la soude de 3 à 6 points. Les écarts entre les teneurs en acide 


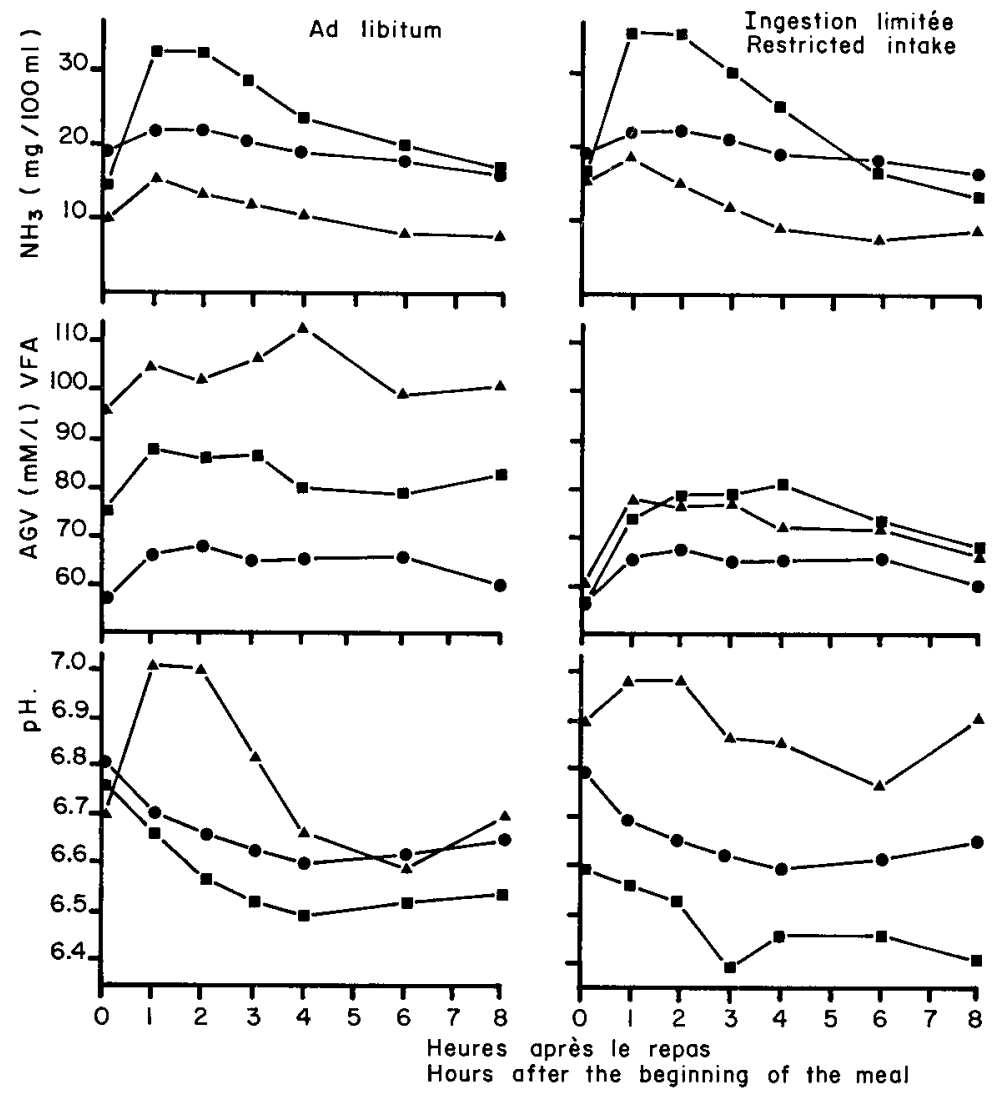

FiG. 1

Influence du traitement et de la limitation de l'ingestion sur la composition du jus de rumen.

Effect of treatment and of feed intake restriction on rumen juice composition.

Légende : cf. figure 2.

Lines : cf. figure 2.

propionique ont été très réduits et les augmentations de teneurs en acide acétique ont été accompagnées d'une baisse des teneurs des autres acides, principalement du butyrique.

\section{3. $\mathrm{NH}_{3}$}

Les teneurs en ammoniac du jus de rumen ont été maximales une heure après la distribution de l'aliment concentré et n'ont jamais été inférieures à $7 \mathrm{mg} / 100 \mathrm{ml}$. Le traitement de la paille à l'ammoniac a augmenté ces teneurs de façon significative, alors que celui à la soude les a abaissées de façon également significative.

La limitation des quantités de paille distribuées n'a eu, en moyenne, aucun effet sur la teneur en ammoniac du jus de rumen. 


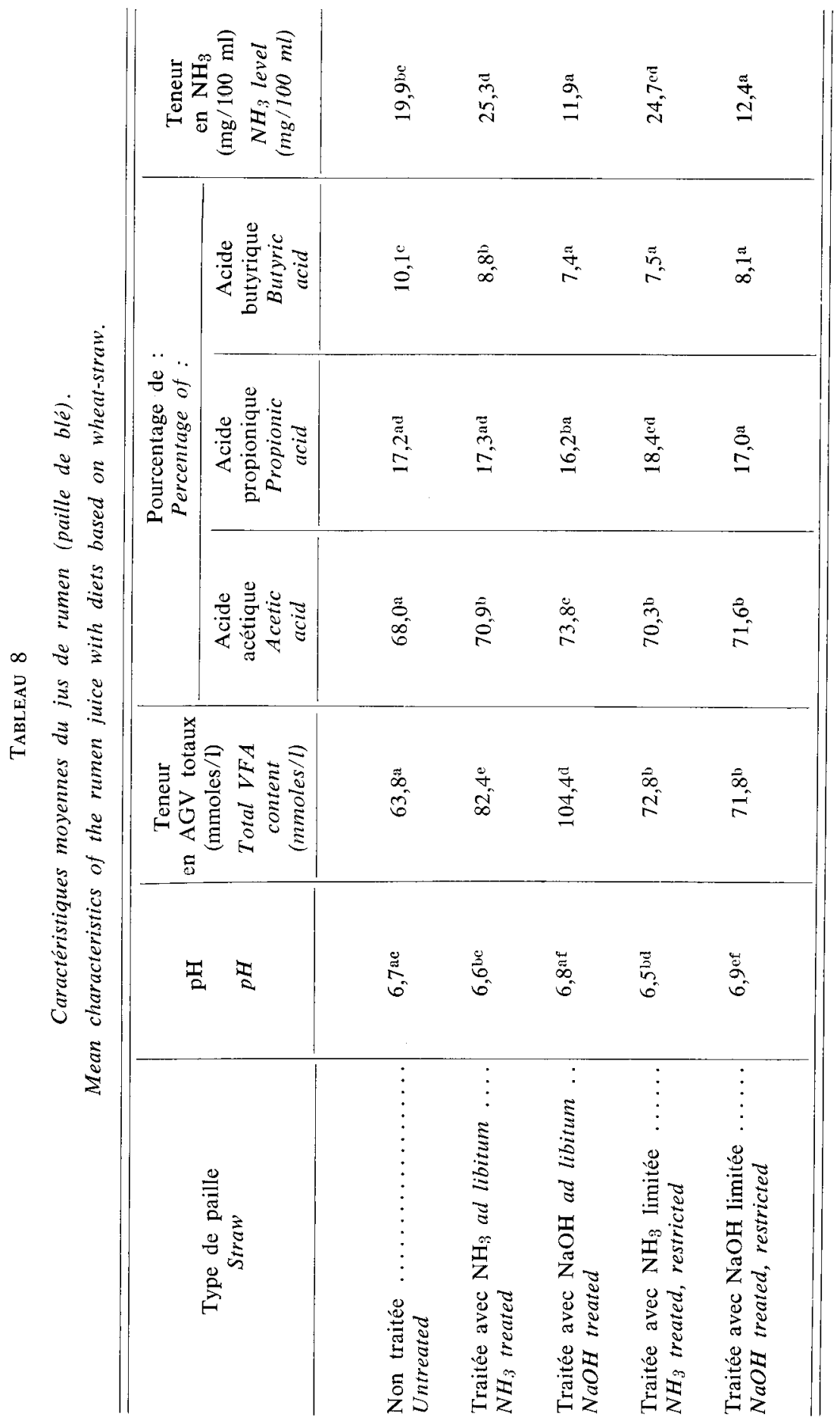




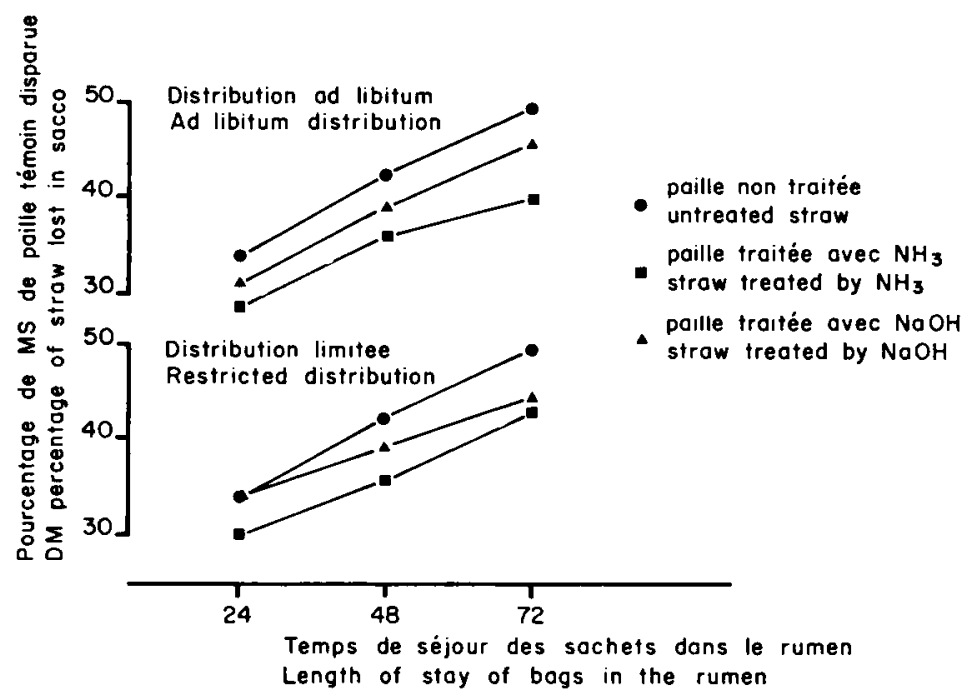

FIG. 2

Activité cellulolytique induite par les différents régimes de paille de blé.

Cellulolytic activity caused by the different diets including wheat-straw.

Note : Les moutons reçoivent les 5 régimes à base de paille de blé. Dans les sachets se trouve seulement la paille non traitée.

Sheep were given the 5 diets based on wheat straw. Bags only included untreated straw.

\section{TABleau 9}

Activité cellulolytique $\left({ }^{*}\right)$ et aptitude à la digestion $(* *)$ des différentes pailles de blé. Cellulolytic activity and digestion rate of wheat-straws.

\begin{tabular}{|c|c|c|}
\hline $\begin{array}{c}\text { Régime } \\
\text { Diet }\end{array}$ & $\begin{array}{c}\text { Activité } \\
\text { cellulolytique (\%) } \\
\text { Cellulolytic activity }\end{array}$ & $\begin{array}{c}\text { Aptitude } \\
\text { à la digestion (\%) } \\
\text { Digestion rate }\end{array}$ \\
\hline $\begin{array}{l}\text { Paille normale } \ldots \ldots \ldots \ldots \ldots \ldots \ldots \ldots \\
\text { Normal straw }\end{array}$ & $42,5 \pm 2,0^{a}$ & $39,6 \pm 0,9^{a}$ \\
\hline $\begin{array}{l}\text { Paille }+\mathrm{NH}_{3} \text { ad libitum } \ldots \ldots \ldots \ldots \ldots \ldots \\
\mathrm{NH}_{3} \text { treated straw }\end{array}$ & $35,9 \pm 1,2^{b}$ & $46,6 \pm 0,6^{b}$ \\
\hline $\begin{array}{l}\text { Paille }+\mathrm{NaOH} \text { ad libitum } \ldots \ldots \ldots \ldots \ldots \\
\mathrm{NaOH} \text { treated straw }\end{array}$ & $39,2 \pm 3,8^{a b}$ & $53,9 \pm 1,2^{\mathrm{c}}$ \\
\hline $\begin{array}{l}\text { Paille }+\mathrm{NH}_{3} \text { limitée } \ldots \ldots \ldots \cdots \cdots \cdots \\
\mathrm{NH}_{3} \text { treated straw, restricted }\end{array}$ & $36,0 \pm 2,9^{\mathrm{b}}$. & 一 \\
\hline $\begin{array}{l}\text { Paille }+\mathrm{NaOH} \text { limitée } \ldots \ldots \ldots \ldots \ldots \ldots \\
\mathrm{NaOH} \text { treated straw, restricted }\end{array}$ & $39,1 \pm 3,8 \mathrm{ab}$ & 一 \\
\hline
\end{tabular}

(*) Mesure par disparition de la paille non traitée en 48 heures dans le rumen des animaux recevant les différents régimes.

Estimation by disappearance of untreated straw during $48 \mathrm{hrs}$ in the rumen of animals fed different diets.

(**) Mesure par disparition des différentes pailles en 48 heures dans le rumen d'animaux recevant un foin identique de luzerne.

Estimation by disappearance of different straws during $48 \mathrm{hrs}$ in the rumen of animals fed the same lucerne hay. 


\section{Activité cellulolytique (fig. 2 et tabl. 9)}

Les traitements de la paille, surtout celui à l'ammoniac, ont abaissé la vitesse de digestion de la paille placée dans les sachets suspendus dans le rumen.

\section{G. Vitesse de digestion des pailles de blé}

Au bout de 48 heures de séjour dans le rumen des animaux recevant du foin de luzerne, la digestibilité en sachets des pailles de blé a été, respectivement de 39,6 pour la paille non traitée, 46,6 pour celle traitée avec l'ammoniac et 53,9 pour celle traitée à la soude.

\section{Discussion - Conclusion}

Bien que ses pourcentages de fixation ne soient pas très élevés, l'ammoniac a augmenté notablement la teneur en azote des fourrages étudiés. Ceci est conforme aux résultats rapportés par de nombreux auteurs : WaIss et al. (1972); HaRT et al. (1975) ; GarretT et al. (1979) ; Kernan et al. (1979 et 1981) ; Cordesse \& Tabatabai (1981)... Les augmentations de teneurs en matières azotées (MAT) citées dans la bibliographie sont en effet, pour les pailles, comprises entre 1,5 (dans le cas d'un traitement trop peu efficace) et 9 p. 100. Pour les foins, les augmentations peuvent être cependant plus élevées (Dulphy et al., 1984). Soulignons cependant qu'avec la paille de blé nous n'avons pas atteint la teneur en MAT de $100 \mathrm{~g} / \mathrm{kg}$ de MS qui pourrait être retenue comme critère d'un traitement réussi.

Notre objectif principal était de comparer les effets d'un traitement à l'ammoniac à ceux d'un traitement à la soude. Avec les techniques de traitement que nous avons utilisées il apparaît que les ingestibilités moyennes des fourrages après traitement sont comparables pour les deux alcalis utilisés ( 6 p. 100 d'écart seulement, dû à la seule paille de riz). Par contre, le traitement à la soude que nous avons utilisé a amélioré un peu plus la digestibilité de la matière organique des fourrages étudiés que celui à l'ammoniac. Ces résultats correspondent globalement à ceux de la bibliographie (Borhami \& Johnsen, 1981 ; Otim, 1979 ; Frenzel \& Pfeffer, 1979) mais nous ne les discuterons pas car ils peuvent être inversés si le traitement à l'ammoniac est effectué dans de bonnes conditions (Sundstol, SAID \& ARnason, 1979 ; Horton et al., 1982 ; WYLIE, 1981).

L'augmentation par rapport aux fourrages témoins des teneurs en matières azotées non digestibles nous paraît plus intéressante à examiner. En effet, cette teneur a augmenté de $22 \mathrm{~g}$ en moyenne après le traitement à l'ammoniac contre seulement

$2 \mathrm{~g}$ après le traitement à la soude. L'augmentation observée peut résulter :

— soit de l'existence d'azote apporté par l'ammoniac, solidement fixé par des réactions chimiques sur les parois non digestibles et donc non libéré dans le rumen (MEschy, 1984),

- soit d'une fermentation plus importante dans le gros intestin, due à une baisse de la digestion dans le rumen, elle-même causée par une plus faible activité 
cellulolytique et/ou une augmentation de la vitesse de transit induite par le traitement à l'ammoniac,

- soit des deux phénomènes à la fois.

Avec le traitement à la soude, la seconde hypothèse est la scule possible, mais l'effet correspondant dans nos essais est faible, plus faible que ce que nous avions déjà trouvé (Dulphy et al., 1982 a). Cet effet a aussi été signalé par ailleurs (Levy et al., 1977). Dans ces conditions, ce serait surtout le premier phénomène qui expliquerait l'augmentation de l'azote dans les fèces après le traitement à l'ammoniac. Des faibles digestibilités de l'azotc apporté par ce traitement ont en effet déjà été observées (Horton et al., 1982 ; Borhami \& JohnSEN, 1981 ; Borhami et al., 1982 ; Stallcup et al., 1982). Une partic de l'azote apporté par l'ammoniac pourrait donc ne pas être libérée au cours de la digestion. Cette partie représente environ respectivement 29,33 et 44 p. 100 pour le foin, la paille de blé et la paille de riz (rapport entre la teneur supplémentaire en azote non digestible et l'azote total apporté par l'ammoniac). Nous avons trouvé 36 p. 100 pour une série de 6 foins (Dulphy et al., 1984). Aвidin \& Kempton (1981) signalent que 35 p. 100 de l'azote de l'ammoniac est inutilisable dans lc rumen. LAWLOR et O'SHEA (1979) citent même une valeur de 58 p. 100 pour l'azote irréversiblement lié. On tire une valeur de seulement 18 p. 100 des travaux de GoRdon \& Chesson (1983). La quantité d'azote provenant de l'ammoniac et inutilisable dans le tube digestif semble donc variable, mais il est probable que l'évaluation de cettẹ fraction est très imprécise. Ce phénomène mériterait d'être examiné de façon plus approfondie.

Les résultats obtenus avec les pailles distribuées en quantité limitée confirment aussi la première hypothèse. En effet, cette limitation doit ralentir la vitesse de passage dans le rumen et donc améliorer la part de la digestion dans cette partie du tube digestif, bien que la digestibilité de la cellulose brute augmente peu. Malgré cela la teneur en matières azotées non digestibles des fourrages traités avec $\mathrm{NH}_{3}$ ne change pas.

La rétention de l'azote ingéré provenant des régimes à base de paille traitée à l'ammoniac, et donc de la paille elle-même, est faible, non seulement à cause de ce qui est perdu dans les fèces et que nous avons discuté plus haut, mais aussi à cause de pertes non négligeables dans l'urine, surtout avec la paille distribuée à volonté. Par contre, le régime à base de paille traitée à la soude s'est bien comporté. Le régime à base de paille traitée à l'ammoniac et distribué en quantité limitée s'est aussi bien comporté. Ces différences proviennent-elles de différences de la synthèse bactérienne dans le rumen. Nous ne le savons évidemment pas, mais cette hypothèse serait à étudier, une plus faible synthèse pour la paille traitée à l'ammoniac s'expliquant par l'effet combiné d'une faible activité cellulolytique et d'une vitesse de transit élevée.

Stallcup et al. (1982) signalent aussi une relativement faible rétention azotée avec un fourrage traité à l'ammoniac, par rapport au même non traité. Pour BoRHAMI \& JoHNSEN (1981) par contre, bien que l'azote soit augmenté dans les fèces par l'apport de paille traitée à l'ammoniac, la quantité d'azote retenu est équivalente pour la paille traitée à l'ammoniac et celle traitée à la soude, à même apport azoté.

Les caractéristiques de la digestion n'ont également été enregistrées que pour la paille de blé. Les teneurs en $\mathrm{AGV}$ et en ammoniac du jus de rumen semblent normales. Les traitements augmentent la teneur en AGV, ce qui est classique (Dulphy et al., 1983 a ; Al Rabbat \& Heaney, 1978 ; O Ol et al., 1979). Cette teneur 
est plus forte après le traitement à la soude qui entraîne une digestibilité de la paille plus élevée et correspond aux résultats de BoRHAMI \& JoHNSEN (1981). La teneur en ammoniac dans le rumen est plus élevée après traitement à l'ammoniac, ce qui est normal et correspond d'ailleurs à un léger excès des PDIN par rapport aux PDIE ingérés et à la faible synthèse microbienne apparente observée. Malgré un apport non négligeable d'ammoniac dans ce cas, les teneurs n'atteignent pas des valeurs excessives à cause de l'ingestion lente de la paille et de la libération probablement non immédiate de l'ammoniac (Cordesse \& Tabatabai, 1981 b). Le pH du jus de rumen a été légèrement plus élevé avec la paille traitée à la soude, à cause de l'effet basique de la soude (Dulphy, 1983 a), mais les écarts enregistrés sont faibles entre les deux types de traitement.

La baisse de l'activité cellulolytique après les traitements, surtout celui à l'ammoniac, est, par contre, curieuse. Ceci est compensé par une aptitude à la digestion plus élevée pour les pailles traitées, surtout celle traitée à la soude, mais n'a pas, à notre connaissance, été déjà signalé. Les conséquences de ce fait ne peuvent cependant être déduites d'un seul essai sur un seul fourrage. S'il était confirmé, il pourrait expliquer une faible synthèse microbienne apparente dans le rumen. Il pourrait expliquer aussi une reprise des fermentations dans le gros intestin, mais cela ne semble pas le cas d'après nos observations.

Un autre objectif de nos essais était de mesurer l'effet de l'apport d'amidon sur la digestibilité de la paille de riz traitée à l'ammoniac. Cet effet a été faible, contrairement à nos essais précédents (Dulphy et al., 1982 b, 1983 a) mais cela est peut-être dû au fait que le concentré n'a pas dépassé 35 p. 100 de la ration. Par ailleurs, les quantités ingérées de paille traitée à l'ammoniac n'ont pas été très élevées. Or, nous savons que l'effet de l'amidon est amplifié par l'élévation du niveau alimentaire. Il est possible aussi qu'une certaine atténuation des phénomènes d'interaction que nous avons voulu mesurer soit due au fait que les teneurs en ammoniac dans le rumen soient plus élevées avec les pailles traitées à l'ammoniac qu'avec celles traitées à la soude.

Finalement, bien que légèrement moins efficace que le traitement à la soude, le traitement à l'ammoniac que nous avons utilisé, a permis une amélioration notable de la valeur alimentaire des trois fourrages pauvres. Par contre, comme dans nos essais sur foins (Dulphy et al., 1984), les résultats que nous avons obtenus indiquent clairement qu'il faut approfondir la question de la valeur azotée de ces fourrages traités à l'ammoniac et rechercher qu'elle est la signification de la faible activité cellulolytique induite par leur ingestion.

\section{Summary}

Compared effects of ammonia and soda-treatment on feeding values of poor roughages

In 3 trials with poor-roughages (a late harvested grass hay, a wheat straw and a rice straw) the effects of $\mathrm{NaOH}$ treatment were compared to those of a $\mathrm{NH}_{3}$ treatment. Ammoniatreatment was made with $40 \mathrm{~g}$ of $\mathrm{NH}_{3}$ per $\mathrm{kg}$ using the Norvegian method in August. Soda treatment was performed $48 \mathrm{~h}$ before feed distribution using a semi-wet process $(2.5 \mathrm{l}$ of a solution containing $16 \mathrm{~g} \mathrm{NaOH} / \mathrm{kg}$ forage). 
Roughages were given to normal sheep in the following conditions :

- untreated forage, ad libitum;

- $\mathrm{NH}_{3}$-treated forage, ad libitum;

- NaOH-treated forage, ad libitum;

- $\mathrm{NH}_{3}$-treated forage, restricted to the same level as untreated;

- NaOH-treated forage, restricted but only for rice straw.

Moreover, wheat straw was given to rumen fistulated sheep, in the above conditions.

Wheat and rice straws were supplemented with concentrates. The influences of two types of concentrates (maize and beet pulp) (tabl. 2) were also compared with the rice straw.

The chemical composition of roughages and concentrate are given in tables 1 and 3 .

Ammonia treatment increased the crude protein content of the 3 roughages especially for hay $(+87 \mathrm{~g} / \mathrm{kg} \mathrm{DM})$. However, for wheat straw, the crude protein level only reached a low value $(85 \mathrm{~g} / \mathrm{kg} \mathrm{DM})$. Feed intake and digestibility of all the forages studied are indicated in tables 4,5 and 6 .

Both treatments greatly increased the voluntary feed intake of the roughages studied in the same way for hay and wheat straw $(+37$ p. 100 on an average). NaOH-treatment was more efficient on rice straw $\left(+62\right.$ p. 100 , as opposed to +31 p. 100 for $\mathrm{NH}_{3}$ treatment).

Both treatments increased organic matter digestibility $\left(+8.9\right.$ with $\mathrm{NH}_{3}$ and +13.5 with $\mathrm{NaOH}$ ), especially for the straws, in which soda was more efficient than ammonia. Replacing " maize » concentrate by pulp concentrate had only a limited effect on the diges. tibilities of the rice straw whether it was treated or not by $\mathrm{NH}_{3}$.

Ammonia-treatment strongly increased the indigestible crude protein content of the forages $(+22 \mathrm{~g} / \mathrm{kg} \mathrm{DM})$. This level was higher with "maize» concentrate, compared to «pulp » concentrate.

Nitrogen retention was higher in animals given $\mathrm{NaOH}$-treated wheat straw (tabl. 7). For this diet based on wheat straw the volatile fatty acids concentration in the rumen juice was higher with the $\mathrm{NaOH}$-treatment than with the $\mathrm{NH}_{3}$-treatment (88 against $78 \mathrm{mmo}-$ le/l; tabl. 8 and fig. 1). By contrast, the $\mathrm{NH}_{3}$ concentration in the rumen juice was higher in the $\mathrm{NH}_{3}$-treated straw $(25 \mathrm{mg} / 100 \mathrm{ml})$ and was harmless for the animals. It was lower for the $\mathrm{NaOH}$ treated straw $(12 \mathrm{mg} / 100 \mathrm{ml})$.

The straw treatments, especially with ammonia, decreased the cellulolytic activity of rumen microflora (tabl. 9 and fig. 2).

These results are discussed. In spite of a slightly lower feed efficiency when compared to $\mathrm{NaOH}$-treatment, $\mathrm{NH}_{3}$-treatment increased the value of poor roughages. But the problem of the nitrogen value significance of $\mathrm{NH}_{3}$-treated forages remains to be solved, as that of the low cellulolytic activity due to their consumption.

Key words: Hay, straw, alcali treatment, intake, digestibility.

Reçu en janvier 1984. Accepté en mai 1984.

\section{Références bibliographiques}

Abidin Z., Kempton T.J., 1981. Effects of treatment of barley straw with anhydrous ammonia and supplementation with heat-treated protein meals on feed intake and liveweight performance of growing lambs. Anim. Feed Sci. Technol., 6, 145-155.

Al-Rabrat M.F., Heaney D.P., 1978. The effects of anhydrous ammonia treatment of wheat straw and steam cooking of aspen wood on their feeding value and on ruminal microbial activity. II. - Fermentable energy and microbial growth derived from ammonia nitrogen in the ovine rumen. Can. J. Anim. Sci., 58, 453-463. 
Borhami B.E.A., Johnsen F., 1981. Digestion and duodenal flow of ammonia-treated straw, and sodium hydroxide treated straw supplemented with urea, soybean meal or fish viscera silage. Acta Agric. Scand., 31, 254-260.

Borhami B.E.A., Sundstel F., Garmo T.H., 1982. Studies on ammonia-treated straw. II. - Fixation of ammonia in treated straw by spraying with acids. Anim. Feed. Sci. Technol., 7, 53-59.

Chenost M., Grenet E., Demarquilly C., Jarrige R., 1970. The use of the nylon bag technique for study of forage digestion in the rumen and for predicting feed value. Proc. XI Int. Grassld Congress, 697-701.

CoRdesse R., 1982. Une solution pratique pour le traitement de vos pailles à l'ammoniac. L'Elevage Bovin, 114, 36-40.

Cordesse R., Taba-Tabai M., 1981 a. Alimentation d'agneaux à partir de la paille traitée à l'ammoniac. I. - Valeur nutritive, croissance et qualité des carcasses des animaux. Ann. Zootech., 30, 137-149.

CoRdesse R., TABA-TABAi M., 1981 b. Alimentation d'agneaux à partir de la paille traitée à l'ammoniac. II. - Cinétique biochimique de la dégradation dans le rumen de la paille. Ann. Zootech., 30, 299-312.

Dulphy J.P., Breton J., Bienaime A., Louyot J.M., 1982 a. Etude de la valeur alimentaire des pailles de céréales traitées ou non à la soude. I. - Influence du traitement à la soude. Ann. Zootech., 31, 195-214.

Dulphy J.P., Kouassi A., BiEnaime A., 1982 b. Etude de la valeur alimentaire des pailles de céréales traitées ou non à la soude. II. - Influence de la nature du complément énergétique. Ann. Zootech., 31, 215-232.

Dulphy J.P., Breton J., Louyot J.M., Bienaime A., 1983 a. Etude de la valeur alimentaire des pailles de céréales traitées ou non à la soude. III. - Influence du niveau d'apport d'aliment concentré. Ann. Zootech., 32, 53-80.

Dulphy J.P., Bienaime A., 1983 b. Etude de la valeur alimentaire des pailles de céréales traitées ou non à la soude. IV. - Influence du nombre de distributions de l'aliment concentré et de l'addition de bicarbonate de sodium. Ann. Zootech., 32, 81-92.

Dulphy J.P., Zwaenepoel P., Komar A., Aboulfaraj S., 1984. Valeur alimentaire des foins traités à l'ammoniac. Ann. Zootech., 33, 41-54.

Frenzel E., Pfeffer E., 1979. Comparison of feeding value of straw treated with ammonia and that treated with alcali. Wirtsch. Futter, 25, 193-197.

Garrett W.N., Walker H.G., Kohler G.O., Hart M.R., 1979. Response of ruminants to diets containing sodium hydroxide or ammonia treated rice straw. J. Anim. Sci., 48, 92-103.

Gordon A.H., Chesson A., 1983. The effect of prolonged storage on the digestibility and nitrogen content of ammonia-treated barley straw. Anim. Feed Sci. Technol., 8, 147-153.

Hart M.R., Graham R.P., Hanni P.F., Rockwell W.C., Walker H.G., Kohler G.O., Waiss A.C., GarretT W.N., 1975. Processing methods to improve the feed value of rice straw. Feedstuffs, 47, 22.

Hartley R.D., Jones E.C., 1978. Effect of aqueous ammonia and other alcali on the in vitro digestibility of barley straw. J. Sci. Food. Agric., 29, 92-98.

Horton G.M.J., Nicholson H.H., Christensen D.A., 1982. Ammonia and sodium hydroxide treatment of wheat straw in diets for fattening steers. Anim. Feed Sci. Technol., 7, 1-10.

I.N.R.A., 1978. Alimentation des ruminants. Ed. I.N.R.A. Publications, route de Saint-Cyr, 78000 Versailles.

JACKson M.G., 1977. Review article : the alcali treatments of straw. Anim. Feed Sci. Technol., 2, 105-130.

Kernan J.A., Coxworth E.C., 1981. New crop residues and forages for western Canada : assessment of feeding value in vitro and response to ammonia treatment. Anim. Feed Sci. Technol., 6, 257-271. 
Kernan J.A., Crowle W.L., Spurr D.T., Coxworth E.C.. 1979. Straw quality of cereal cultivars before and after treatment with anhydrous ammonia. Can. J. Anim. Sci., 59, 511-517.

LAWLOR M.J., O'SHEA J., 1979. The effect of ammoniation on the intake and nutritive value of straw. Animal Feed Sci. Technol., 4, 169-175.

Levy D., Holzer Z., Neumark H., Folman Y., 1977. Chemical processing of wheat straw and cotton by-products for fattening cattle. I. - Performance of animals receiving the wet material shortly after treatment. Anim. Prod., 25, 27-37.

Meschy F., 1984. Contribution à l'étude de la valorisation des pailles de céréales. Thèse de Docteur-Ingénicur. Université de Dijon, $98 \mathrm{p}$.

Oji U.I., Mowat D.N., Buchanan-Smith J.G., 1979. Nutritive value of thermoammoniated and steam treated maize stover : rumen metabolites and rate of passage. Anim. Feed Sci. Technol., 4, 187-197.

OTim J.J., 1979. Physiological and nutritional effects on animals of feeding chemically treated wheat straw. Diss. Abstr. Int. B, 40, 6, 2449-2450.

Solaiman S.G., Horn G.W., Owens F.N., 1979. Ammonium hydroxide treatment on wheat straw. J. Anim. Sci., 49, 802-808.

Stallcup O.T., Harrison K.L., Kreider D.L., Bailey P., 1982. Ammonia treatment of bermudagrass hay. Arkansas Farm Research, 31, 9.

Sundstal F., Coxworth E., Mowat D.N., 1978. Improving the nutritive value of straw and other low quality roughages by treatment with ammonia. World Anim. Review, 26, 13-21.

Sundstøl F., Said A.N., Arnasson J., 1979. Factors influencing the effect of chemical treatment on the nutritive value of straw. Acta Agric. Scand., 29, 179-190.

Waiss A.G., Guggolz J., Kohler G.O., Walker H.G., Garrett W.N., 1972. Improving digestibility of straws for ruminant feed by aqueous ammonia. J. Anim. Sci., 35, 109-112.

WYLIE A.R.G., 1981. The effect of ammonium hydroxide and sodium hydroxide on the nutritional value of hay. Rec. Agric. Res., 29, 5-9.

XANDE A., 1978. Valeur alimentaire des pailles de céréales chez le mouton. II. - Influence de l'espèce, de la variété et du séjour sur le sol avant ramassage sur la valeur alimentaire des pailles de céréales. Ann. Zootech., 27, 601-616. 